\title{
Digital Simulation: a new kind of artifice?
}

\author{
Colette Tron \\ Alphabetville Organization \\ 9, traverse de la roseraie, 13007 Marseille, France \\ coletron@orange.fr
}

\begin{abstract}
Digital simulation is a process of calculation technologies in the goal of modelling real phenomena and proposing some mimetic or theoretical formalizations of them. The computers interfaces make appear some calculated figures that have been automatically treated by the machine.

In the art field, the modelling of the symbolic forms through the computer programming and the calculated simulation seems to be a revolution for the state and the status of the representation. How is it made and where is it situated? By effect how to situate and define it, from real to virtual, from mimetism to abstraction, etc? And what is the nature of this new kind of artifice, produced by the calculation technology?
\end{abstract}

Simulation. Calculation. Modelling. Technology. Representation. Materiality. Art. Creation. Aesthetic.

\section{INTRODUCTION}

Digital simulation is a process of calculation technologies in the goal of modelling real phenomena and proposing some mimetic or theoretical formalizations of them. The computers interfaces make appear some calculated figures that have been automatically treated by the machine - the abstract machine.

In addition that, as say the artist Edmond Couchot and the philosopher Norbert Hillaire in their essay "The digital art, or how technology comes to the art world ", "the digital simulation models are already, as each scientific model, some formalized interpretations of the reality" and in this way "strongly direct the aesthetic tendencies", the idea here is to observe the constituents and the working of the morphogenesis, from the computer program to the symbolic form, and to look at the articulation of techné and logos into the simulated representation.

This brings us the problem of defining what are these systems of representation, virtual or immaterial. Which kind of art is coming from them? What does the matrix generates? Which sorts of materiality are they made of? What the signs of this representation are?

In the art field, the modelling of the symbolic forms through the computer programming and the calculated simulation seems to be a revolution for the state and the status of the representation. How is it made and where is it situated? By effect how to situate and define it, from real to virtual, from mimetism to abstraction, etc? And what is the nature of this new kind of artifice, produced by the calculation technology?

In this proposition, we will also try to see in which dimension the simulation, and more generally the computerization of representation systems, reinforce and actualize the relationship between art and science, and modify the role of techno-artistic tools. In digital art, the material of the artist is becoming the technology and the production of symbolic forms depends of its process.

Anticipating possible misunderstanding about the meaning of device, which is an usual name, we have decided to use the term of "artifice" to refer to the representation of this new kind of artefact, in distinction with technological device.

\section{SIMULATIONS}

Simulation is historically linked to the domain of both science and the arts. In science one refers to the simulation of phenomena as opposed to experimentation and in art it is a matter of simulation as opposed to enactment. We will be carefully examining both these notions further on. Notions that touch upon imitation. 
Technological simulation is based on digital or data processing simulation produced by calculating machines in the form of computers.

Here it is a question of comparing the notion of simulation between art and science and most especially in conceptions tied to artistic representation to show the advances of simulation via digital technology.

On a technical level the latter links science to art whereas they are perhaps divided on a conceptual level, to seemingly create a renewed relationship between art and the technical.

As for digital technologies applied to art, or digital art, the term simulation tends to apply to technological and artistic fields and there may even be confusion concerning the way they intersect.

Hence "References to simulation, while crossing through all of philosophy are not at all obvious particularly when it is a question of computing." taken from a quote by Francis Rousseau, researcher at IRCAM in an article entitled "Informatique, simulacre and simulation". He goes on to add: "Basically it is a question of deciding if computer simulations open the way to a new kind of simulation."

From science to art, what is the nature of this new kind of artifice?

\section{TECHNOLOGY AND ART}

According to Edmond Couchot and Norbert Hillaire in their work L'art numérique, ou quand la technologie vient au monde de l'art, "digital technologies are for the most part technologies of simulation. They go on to say that "computer science and its formalized models imply new states of technology."

In the case of artistic instrumentation this new state of technology has an influence upon modes of production in artwork. For indeed, technology leaves a definite imprint on the way we represent the world. And all art and periods of art are sustained by one or more technologies that configure the form and content of artwork in a more or less meaningful way.

But to what extent? What role does technology play in digital technologies? And how is it represented: in its form, process, language, it's symbolic forms, its perceptive, sensorial and cognitive effects?

To broach this analysis several of the following premises should be examined.

\subsection{Simulation in science}

In the scientific domain, simulation is a method that consists of theoretically studying the activity, or the action of a real phenomenon, or rather studying the results an action has upon a real element. Simulation replaces experimentation while maintaining identical frameworks and then makes observations about the results.

The Wikipedia encyclopaedia indicates that: "A scientific model seeks to represent empirical objects and phenomena and physical processes in a logical and objective way. Modelling refers to the process of generating a model as a conceptual representation of some phenomenon. The output are elements to be studied, data, parameters and limitations are elements that influence the model's behaviour. Simulation is the implementation of a model, the data, the parameters, limitations and the obtained results."

\subsection{Simulation in the arts}

Simulating is feigning, adopting attitudes and the behaviour of a human being or an object. This is particularly true for the theatrical arts. It is mimetism or imitation without necessarily intending to create illusion.

The process of simulacrum is distinct from that of simulation. Firstly because it does not identically copy the original, but rather frees itself of outward appearance, replacing it and putting forward an altered form. Theories or signs and languages are veils, covering reality and thus no longer represent or portray it, instead they transform and reengineer. According to Jean Baudrillard and his analyses in "Simulacres et simulation" and "L'échange impossible" wherein he evokes the virtual, he goes as far as to say "the real no longer exists." Through a profusion of simulacra, accumulation and mediatization and processes of reproduction, contemporary society will have lost its relationship to the original, its references or, in other words, the real. Jean Baudrillard also claims that simulation today precedes the real, producing it and replacing it and in the case of the virtual I might add, excluding it.

In fact when referring back to digital simulation we find that procedures of calculation augment the virtual possibility to solve complex problems and the real model, the referent, is replaced regarding the production of results in favour of the theoretical model and its modelling, its computerized formalization.

Simulated representation in terms of technique of representation tends to dominate the sciences and the arts. It takes on a predominant role for it 
produces formal results whether in their virtual state or when transposed to the real (as is the case for architecture). It is important to keep in mind that the real is and remains the primary element in both forms of simulation despite its elimination by the simulated representation.

\subsection{Digital simulation}

Digital simulation is based on calculation, its starting point that of representation of a phenomenon by an equation.

Wikipedia's article stipulates that : "Thanks to an ever-increasing capacity to calculate and an augmentation of the volume of storage, it is possible to break down a complex phenomenon by thousands, even millions of simple phenomena and thus to calculate the result of complex phenomena." It goes on to say: "Simulation, especially digital, is based on the knowledge of phenomena. Knowledge that can only be obtained by experimentation of anterior and analogous phenomena."

This is noteworthy in the framework of a definition of simulation and the representations that it generates: it builds upon knowledge and the formalization of reality. It is already a type of epistemology, a cognitive and symbolic structuring that allows the reconstitution of studied or theorized phenomena.

On one hand it fuels a logical relationship with the real and on another hand formally models it.

Wikipedia's encyclopaedia also states that "Digital simulations depend upon the use of theoretical models" and "are thus a digital adaptation of mathematical modelling. Graphical interface allows the visualization of the resulting calculations." These interfaces represent a so-called real, theoretically modelized and automatically calculated.

While this digital transcription supposes interesting informative accuracy in the scientific domain, it leaves room for doubt regarding its validity for artistic representation whose rules for an imitation of the real or its restitution have been represented by other models and other rules and even overturned, especially during the $20^{\text {th }}$ century when we look at most of modern and contemporary art's trends and movements.

\section{THE REFIGURING OF PHENOMENA}

If the refiguring of phenomena by simulation has been established as a given fact in science, it is a new system in art and one which will shift the fabrication, comprehension and the way we understand works and representation.

Since the evolution of the Turing machine and Von Neumann's neurons, research in the domain of computing and the development of computers has been built upon the production of an intelligent behavioural machine, one that replicates the way humans act, or at least the way the human brain does, in all its similarity or through its simulation.

All computing procedures are based on a system which does not consist of representing reality, but functions like reality.

Hence, to quote Couchot and Hillaire, in computer or digital simulation, phenomena can be analyzed, calculated, synthesized and reproduced in their behaviours and their actions "after internal laws and processes that structure and bring them to life", and not necessarily according to their exterior appearances (even though this is what they perceptively seem to restitution).

Thus we are confronted with a new type of simulation, and a new kind of artifice, notes Francis Rousseau.

\section{NATURE AND ARTIFICE, SIMULATION AND SIMULACRA}

Indeed, in the artistic field and concerning the creation of forms, it has rarely been a question of reproducing physical and biological mechanisms, with the exception of artificial creatures or sometimes mechanical processes.

But in these situations "internal laws" do not entirely encompass the entire object or figure to be represented, and there is generally a mixture of simulation and simulacra or in other words imitation and transfiguration.

Whereas with digital technologies it becomes possible to completely recompose a phenomenon and to reproduce it, identically reanimating it in accordance to its natural principals. Artificial life and intelligence are the furthest advanced technologies (along with today's genetic algorithms, neuronal networks and other biotechnologies). Likewise these technologies are based on living systems and the study of their natural principals in view of recreating them artificially, notably via computer programs.

The modelling of behaviour, of possibly even complex organisms and their interfacing via programs offers artifices of a new kind, another nature. 
This antinomy is an indication of the perceptive confusion that digital simulation generates ; nature, artifice, the original, duplicate, reproduction, imitation, illusion and simulation interact and intermingle.

In any case, it is undeniable that the relationship between nature and device, natural and artificial, has taken on a new phase which has conceptual consequences in science, art and philosophy.

And now perhaps paradoxically simulation leads us to its contrary, simulacra (an image without the substance or qualities of the original), in terms of a disconnection, with the loss of referent, the original, the real and a transposition into modelling that is more and more abstract, relying only upon calculation. Which leads Jean Baudrillard to say that the virtualization of the world is pulling us away from metaphysics towards pataphysics, or in other words, a lack of meaning. Tying us to nothing and replacing reality with representation. This is what he writes in "L'échange impossible": the real is disappearing, its representation no longer allows us to distinguish nor even to perceive the referent of its duplicate, its figuration, despite the form it takes on.

Are we thus penetrating a new reality? A virtual reality...

Again making reference to Jean Baudrillard: treating representations of our world through simulation (or any form of presentation altogether since the referent has been suppressed), renders generalized simulation indecent. It amounts to the same thing, he says, whereas representation should be an operation that fades out (disappearing) leaving the place for a transfigured re-apparition. "Consequently this disappearance persists and remains active".

When used as a replacement, this capacity of automatic generation of simulated figures, identical to the real, renders autonomous, organic, primal and original and provides for an evacuation of reality.

"In the wakes of simulation, says Baudrillard, not only has the real world disappeared but the question of existence itself no longer has meaning."

\section{MODELING AND REPRESENTATION}

It has been noted that to theoretically model a phenomenon and to develop a simulation, even a digital one, a certain amount of knowledge is necessary. This implies that the phenomenon has already been studied, analyzed and understood, and that one has taken a serious approach as to its functioning.

Inversely we have also seen that the system of calculations that is the basis of digital simulation, allowing the automatic and autonomous resolution of real phenomenon results in a logical solution.

Proximity and autonomy as regards to reality are the two extremes of simulation. It is vital to comprehend and familiarize oneself with a real phenomenon to be able to simulate it and it is necessary to develop theoretical models to generate new results, producing a new reality born of simulation.

Concerning the subject of the modelling of a phenomenon and its simulated representation, it is important to keep in mind that no matter what level of simulation is involved it is structured around a model, be it real or theoretical. It therefore requires a logical, well thought-out and intelligent approach to reality. It becomes a matter of a certain scientific nature wherein analysis and reasoning produce results.

Indeed, Edmond Couchot and Nobert Hillaire maintain "that these models of digital simulation are, like all scientific models, already formalized and rational interpretations of the real" and that "with the digital, science can no longer be interpreted metaphorically" by artists but "establishes its presence in art directly and internally."

What are the implications of this technology for the art? Where does it lead?

What results from a combination of an application of digital simulation and the arts, how does it affect an artist's work, artists who, for the most part apply themselves to the sensitive, the unformulated, feelings and sensation? For whom normally the real is substance : substance to work with, transform, model or free, being energetic, fluid, pliable or resistant, in any case tangible, palpable and perhaps most importantly incapable of being mastered. This would be the definition of an artist's work: an eternal quest of the significant, in permanent movement, never rigid or fixed by representation, the antithesis of anything modelized.

Yet to be more precise, digital simulation relies on theoretical and mathematical models of complete or calculable elements. Moreover, to fabricate a simulation a computer program is composed of a series of actions that have to be predictable and traceable in order to exist. A computer program is predetermined and functions according to results anticipated by the programmer. 
Finiteness and determination are thus required elements of computing.

These two terms refer to concepts that influence the representation of the world towards which they contribute. Indeed, they give us information about the conception of a world we can define, whose content and contours are familiar. A world that is closed, permanent, inert and unchanging. The contrary of an open, infinite vision of the universe, be it infinitely small or immense, of a world in perpetual mutation, undergoing a process of transformation. Irrefutable references available to us in science - and notably reinforced by the discovery of quantum physics - have used the technique for numerous centuries - in art as well something that cannot be ignored. For example, in the Renaissance, the invention of perspective had already put forth a representation that included the infinite, the vanishing point is a good example of this, notes Daniel Arasse in his "Histoires de Peinture". And yet at the time the idea of the infinite was not a popular notion, he says, unacceptable to those in power, particularly the religious institution.

Hence, which re-presentation of the world are computer programs capable of re-constituting since simulation necessitates finitude and calculability?

Digital simulation is therefore an indication of a new state of representation closely connected to a specific state of technique of which digital artwork is an integral part that directly confronts it.

\section{WORKS WITHIN NATURE AND ARTIFICE, LOGIC AND THE POETIC}

Now we will examine and decrypt as an example two digital works of art whose principals and forms call into question the problematic that surfaces from simulation on the cutting edge, that is to say works that employ this new kind of artifice and the kind of simulation it supplies (for what does it contribute and master?), and does it amount to simulacra or not. Finally, is it possible to generate and represent worlds that are open and in movement through digital simulation and models of calculation?

\subsection{Surnatures by Miguel Chevalier}

Sur-Natures is a generative and interactive work of reality developed in 2000 by the artist Miguel Chevalier that takes its inspiration from research conducted at agronomy laboratories which study and simulate the growth of plants. Composed of a series of pieces, this first version of Sur-Natures is constituted of virtual plants and flowers that grow each day in real time on plasma screens or in an inflatable greenhouse. These pure and simple images are in flux, generated in and by time. These virtual flowers follow their own progressive path outside of the normal growth cycle throughout the year. Creations of this sort bring to mind Monet's cosmic sensitivity, his exploration of light and time and his penchant for the series. The technological system was developed by Music2eye, a Parisian artistic collective whose progressive sculptures and installations explore behavioural design, the use of artificial entities inside a creative and interactive process. In Sur-Natures, "calculations anticipate randomness in its growth", after the philosopher Françoise Gaillard, and "this other nature or supernature is at opposite extremes of a still life. It is living, undying, even prolific. And this unpredictable proliferation, while intelligently calculated is delightful" she goes on to say in the exhibition's catalogue.

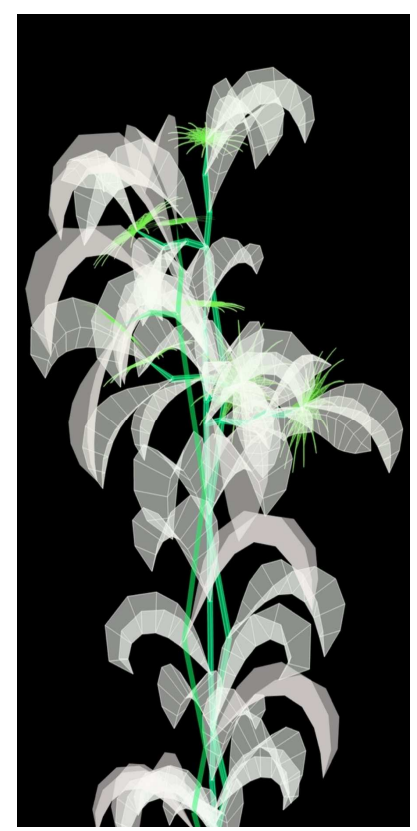

Figure 1: Seed from the herbarium "Sur-Natures" - $M$. Chevalier

By digitally recomposing the biological system, in other words the natural system, their internal mechanism has been imitated or simulated. A simulation both scientific and artistic since it touches upon representation. Unfurling in front of us, animated and artificially produced by software, we discover not the appearance of reality but are confronted with the biological phenomenon of the development of plants as they have been modified by the artist. What is the signification and meaning being addressed here? What does this piece show or conceal? What does it produce? A virtual reality simulating natural reality to perfection? A simulation transformed into simulacra? In any case here we are faced with new technologies producing new artefacts, a new state of technique organizing a new state of art. Finding ourselves in a situation where we are reminded of the philosophy that perhaps there has never been a distinction between nature and device, that for a certain 
science they are on a continuum and that the quest for the original is thus futile.

\subsection{Dirigeable by Etienne Rey}

Dirigeable is an invitation to travel through a sea of artificial creation. This imaginary space is built upon rules of physics corresponding to a sea environment on a microscopic scale. These digital creatures equipped with intelligence group together to generate organized sound. Endowed with characters that form a simple cluster they exchange sound-languages in relationship to one another. In Dirigeable artificial intelligence is designed to be a tool to generate interaction and works like a writing motor. Thanks to algorithms of artificial intelligence the scenario is no longer born of a completed tree structure, instead it relies upon behaviour patterns between entities. This relationship allows room for the development of non-linear interaction, produced from the chance encounters between individuals, according to their respective identities and movement. This supposes a notion of entropy and results in an emergent evolution. A process evolves resulting from the dynamics of self-organization produced from a chain of interaction at the local level.
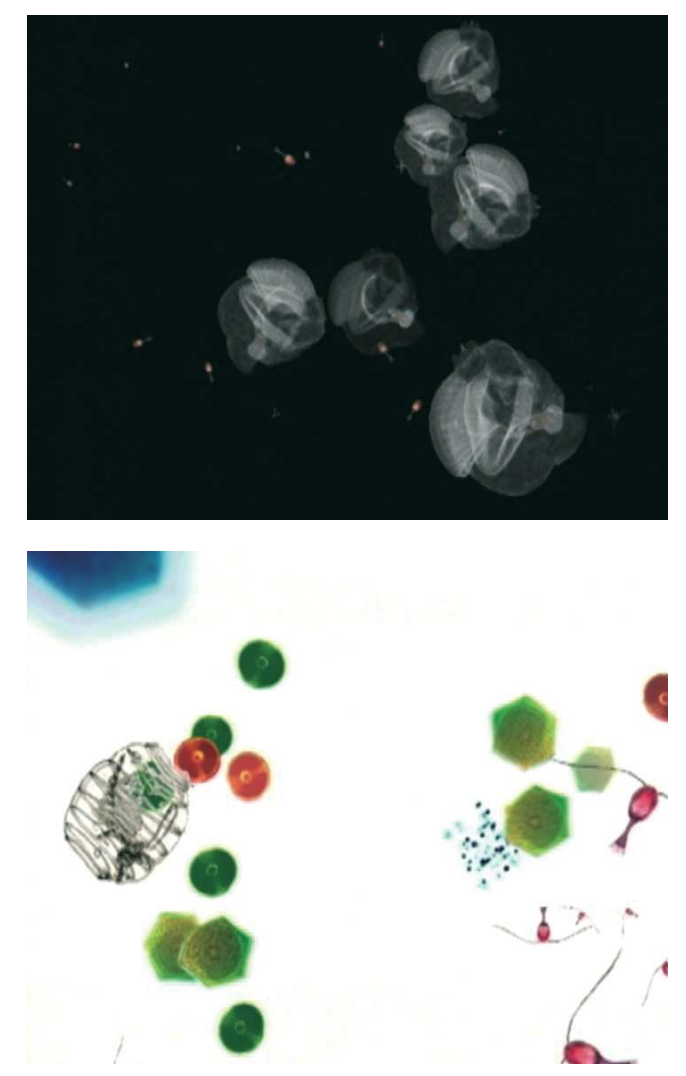

Figure 2: "Dirigeable" - Etienne Rey, motion capture
Based on real models of marine life organisms, here again simulation reconstitutes living systems, their mode of development, growth, interaction and social nature. Following the laws of physics and through the use of artificial intelligence that stimulates them to function in the same way living creatures would, Dirigeable is at one with the biological world. But artifice nonetheless makes itself felt, even on complex levels, the latter meticulously introduced and manipulated. This does much to destabilize our perception : real and imaginary creatures merge, structured behaviour patterns and random generation help relationships form. There is an obvious and subtle intermingling of real and virtual with a non-linear algorithmic composition. The logic of calculation comes to life opening the doors to a process of infinity. And like evolution it brings about emergence and newness.

\subsection{Conclusion}

Plant or animal, biological organism or real model, all form the composite of these two works. The modelling and simulation of true, living referential reality are shaken up by imaginary, unrealistic elements, by a rearrangement of and readjustments to natural processes. And so through the use of reconstructed phenomena available to us thanks to technologies of precise calculation artists have been able to create fictions, tales, chimera and offer up new complex artifices or devices, of unimaginably inventive virtual worlds. An art where what we are shown plays second role and second nature to our fascination with the importance of what is actually taking place.

\section{REFERENCES}

Couchot, E, Hillaire. N. (2003) L'art numérique, éd. Flammarion, Paris.

Rousseau, F. Informatique, simulacre et simulation http://www.ardanti.com/rousseaux/pdf/papiers/infor matiqueSimulacreSimul\%20.pdf (28 April 2011).

Baudrillard, J. (1981) Simulacres et simulation, Galilée, Paris.

Baudrillard, J. (1999) L'échange impossible, Galilée, Paris.

Baudrillard, J. (1997) Illusion, désillusions, esthétiques, éd. Sens et Tonka, Paris.

Arasse, D. (2006) Histoires de peinture, éd. Folio Poche, Paris. 